\title{
Rapid synthesis of CdSe nanocrystals in aqueous solution at room temperature
}

\author{
YILIN WANG*, JIAN PING LU and ZHANG FA TONG \\ College of Chemistry and Chemical Engineering, Guangxi University, Nanning 530004, PR China
}

MS received 25 March 2009; revised 3 June 2009

\begin{abstract}
Water-soluble thioglycolic acid-capped CdSe nanocrystals (NCs) were prepared in aqueous solution at room temperature. We investigated the effects of $\mathrm{pH}$ values on the fluorescence intensity of the as-prepared CdSe NCs, and discussed the influence of the initial $\mathrm{pH}$ values on the fluorescence property. Their mean diameter was estimated to be $1.9 \mathrm{~nm}$ depending on the initial $\mathrm{pH}$ values in the preparation, the photoluminescence quantum yield could reach as high as $1.9 \%$, almost comparable to the CdSe NCs prepared by an organometallic route. Finally, the products were characterized by Fourier transform infrared spectrometry (FTIR), atomic force microscope (AFM) and X-ray powder diffraction (XRD). AFM image showed that the NCs were ball-shaped with good dispersibility. XRD analysis disclosed that the CdSe NCs were of cubic zinc-blended structure.
\end{abstract}

Keywords. CdSe; nanomaterials; semiconductors; luminescence; synthesis.

\section{Introduction}

CdSe nanocrystals (NCs) have gained significant attention in the past decade because of their unique optical properties. Extensive researches have focused on the synthesis (Rogach et al 2000; Jasieniak et al 2005; Manoj et al 2008) of CdSe NCs. Based on their researches, the synthesis of CdSe NCs can be summarized in two chemical routes, one is nonaqueous trioctyl phosphine/trioctyl phosphine oxide (TOP/TOPO) technique, and another is using different thiols as stabilizing agents in aqueous solution. The most popular route for the synthesis of high quality CdSe NCs is nonaqueous technique, which originated from the work of Murray et al (1993) and developed by Peng and Peng (2001). However, a further process is needed for the NCs used in biological system due to as-prepared $\mathrm{NCs}$ often dispersing in nonpolar organic solvents. Under refluxing condition, the watersoluble CdSe NCs were prepared in aqueous solution using thiols as stabilizing agents, which was first reported by Weller's group (Rogach et al 1999). Up to now, many methods (Zhu et al 2000; Chen et al 2008; Xia and Zhu 2008) for preparing CdSe NCs in aqueous solution under refluxing condition have been developed. Recently, some research groups have synthesized water-soluble $\mathrm{CdSe}$ NCs at lower temperature. For example, Han's group (Han et al 2006) synthesized water-soluble CdSe NCs under high-intensity ultrasonic irradiation, however, their photoluminescence properties were not characterized. Yu

\footnotetext{
*Author for correspondence (ylinwang2002@yahoo.com.cn)
}

et al (Deng et al 2006) prepared citrate-stabilized CdSe at $75^{\circ} \mathrm{C}$, after the product was illuminated with natural ambient light for 30 days, the final quantum yield was only little more than $4 \%$. To the best of our knowledge, CdSe NCs with moderate photoluminescence quantum yield have not been prepared directly in aqueous solution at room temperature.

In this paper, a rapid and simple method was reported for synthesizing water-soluble thioglycolic acid-capped $\mathrm{CdSe} \mathrm{NCs}$ at room temperature. We investigated the effects of $\mathrm{pH}$ values on the fluorescence intensity of the as-prepared $\mathrm{CdSe} \mathrm{NCs}$, then, discussed the influence of the initial $\mathrm{pH}$ values on the fluorescence property. Finally, the products were characterized by Fourier transform infrared spectrometry (FTIR), atomic force microscope (AFM) and X-ray powder diffraction (XRD).

\section{Experimental}

\subsection{Materials}

Cadmium chloride hemidihydrate $\left(\mathrm{CdCl}_{2} \cdot 2 \cdot 5 \mathrm{H}_{2} \mathrm{O}\right)$, Se power, sodium borohydride $\left(\mathrm{NaBH}_{4}\right)$, thioglycolic acid (TGA), (all were of analytical reagent grades acquired from the Shanghai Chemical Factory, Shanghai, China) were used for the preparation of CdSe.

\subsection{Method of preparation}

The preparation of CdSe NCs was conducted by modifying the procedures described elsewhere (Gaponik et al 
2002) for making thiol-capped CdTe NCs. Briefly, $0.4567 \mathrm{~g} \mathrm{CdCl}_{2} \cdot 2 \cdot 5 \mathrm{H}_{2} \mathrm{O}$ was dissolved in $100 \mathrm{ml}$ deionized water in a $250-\mathrm{ml}$ three-neck flask, and $0.5 \mathrm{ml}$ TGA was added while stirring, followed by adjusting the $\mathrm{pH}$ to desired values with $1.0 \mathrm{~mol} \cdot \mathrm{L}^{-1} \mathrm{NaOH}$. The solution was deaerated by $\mathrm{N}_{2}$ bubbling for $30 \mathrm{~min}$. Under vigorous stirring, $1.0 \mathrm{ml}$ oxygen-free $\mathrm{NaHSe}$ of $1.0 \mathrm{~mol} \cdot \mathrm{L}^{-1}$ was injected with a syringe to the above solution. When the colour of the solution was changed to orange, CdSe NCs was produced.

\subsection{Characterization}

Absorption and emission spectra were measured using a UV-2102 spectrometer and a RF-5301 fluorescence spectrometer, respectively. Estimates of quantum yields (QY) were obtained by comparing the integrated emission from Rhodamine $6 \mathrm{G}(\mathrm{QY}=95 \%)$ in ethanol with that of $\mathrm{CdSe}$ NCs dispersed in buffer solution $(\mathrm{pH}=4 \cdot 0)$. FTIR spectra were recorded on a Nexus-470 spectrometer. The morphology measurement was performed using a SPA-400 atomic force microscope. X-ray powder diffraction (XRD) was taken on a Rigaku D/max $2500 \mathrm{~V}$ diffractometer equipped with $\mathrm{CuK} \alpha$ radiation $(\lambda=0 \cdot 15406 \mathrm{~nm})$.

\section{Results and discussion}

In the presence of $\mathrm{NaHSe}$, NCs were formed immediately. However, almost no fluorescence was detected. Based on the report that the fluorescence intensity of CdTe solution strongly depended on $\mathrm{pH}$ values (Gao et al 1998), a set of fluorescence intensities under different $\mathrm{pH}$ values from $\mathrm{CdSe}$ were recorded, and figure la displayed the relative fluorescence intensity at different $\mathrm{pH}$ values. It can be seen that the fluorescence intensity reached its maximum at $\mathrm{pH}=4 \cdot 0$, and $\mathrm{pH}$ values both lower and higher than 4.0 resulted in a significant decrease. The research (Bowers et al 2005) on CdSe demonstrated that the photoluminescence of $\mathrm{CdSe} \mathrm{NCs}$ was attributed to defect-related emission. Because of the extremely small diameter, there are many trap sites on the surface of $\mathrm{CdSe}$ NCs, the more the trap sites, the lower the fluorescence efficiency. The synthetic route in aqueous phase, cadmium and thiol were excessive, cadmium thiol complexes were formed in the solution. It was observed that the formation of the cadmium thiol complexes strongly depended on the $\mathrm{pH}$ of the solution, when $\mathrm{pH}$ was less than $4 \cdot 0$, no complexation occurred (Hayes et al 1989). When the CdSe solution becomes acidic, free thiols and cadmium ions will be released from the cadmium thiol complexes, the relative coverage rate of the particle surface with thiols was increased. Therefore, the trap sites on the CdSe surface will be removed, and the fluorescence efficiency was improved. When $\mathrm{pH}<4 \cdot 0$, the thiols attached to the NCs were detached from the surface, more surface defects formed, resulting in a decrease of the fluorescence intensity.

In preparation, the initial $\mathrm{pH}$ values were adjusted to 5.3, 7.4, 9.2 and 11.2 (called samples 1, 2, 3 and 4 below), respectively. We investigated the influence of initial $\mathrm{pH}$ values on the optical properties of CdSe NCs. The original solutions of various initial $\mathrm{pH}$ values were diluted with buffer solution $(\mathrm{pH}=4 \cdot 0)$, and the absorption and fluorescence spectra were shown in figure $1 \mathrm{~b}$. As can been seen, in all cases, the excitonic absorption peak was not very distinct, but it appeared at around $440 \mathrm{~nm}$, indicating the formation of CdSe NCs with wide particle size distribution. The mean diameter was estimated to be $1.9 \mathrm{~nm}$ based on the work of Yu et al (2003). All of the maximum emission peaks were found almost at $524 \mathrm{~nm}$ with a full width at half maximum of about $100 \mathrm{~nm}$, suggesting that the sizes of CdSe NCs were independent of the initial $\mathrm{pH}$ values. Chen et al (2009) disclosed that the initial ratio between $\mathrm{Cd}$ and $\mathrm{Se}$ played a major role in determining the nucleation and growth rate of CdSe NCs. In our experiments, the molar ratio of $\mathrm{Cd} / \mathrm{Se}$ was set to
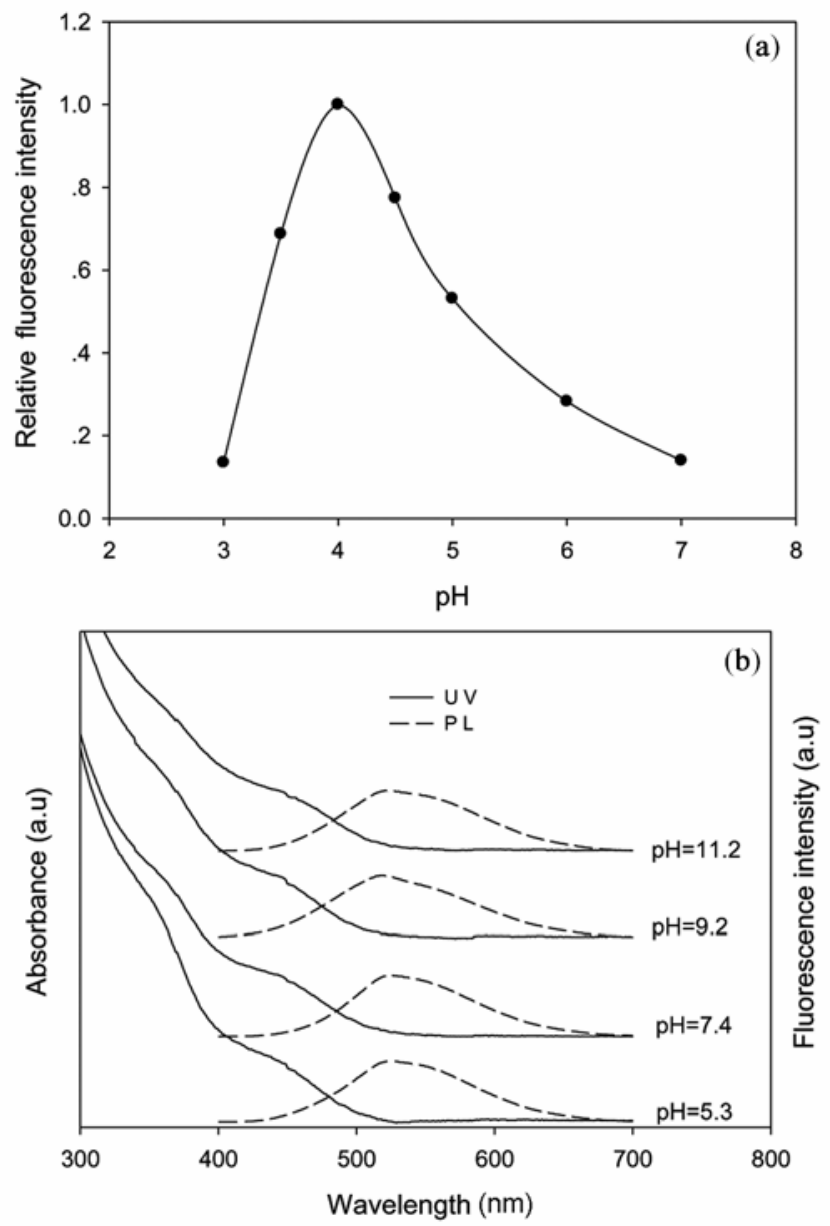

Figure 1. (a) Relative fluorescence intensity of CdSe NCs at different $\mathrm{pH}$ values and (b) absorption and fluorescence spectra of CdSe NCs prepared at different initial $\mathrm{pH}$ values. 
$2: 1$, and the reaction temperature was kept the same Therefore, the emission peaks of all samples almost appeared at the same location. In contrast, under the same condition, the fluorescence intensity varied with the initial $\mathrm{pH}$ values, for samples 1, 2, 3 and 4, the QYs were $1.0 \%, 1.3 \%, 1.5 \%$ and $1.9 \%$, respectively. According to the theory of acid-base equilibrium, the initial $\mathrm{pH}$ value of original solution determines the dissociation state of TGA and the coordination between stabilizer and $\mathrm{Cd}^{2+}$ ion. The dissociation constants of TGA are $\mathrm{p} K_{\mathrm{al}}=3.60$ and $\mathrm{p} K_{\mathrm{a} 2}=10 \cdot 56$. When $\mathrm{pH}$ was less than $3 \cdot 60$, the precursor solution was milk-like, no cadmium thiol com-

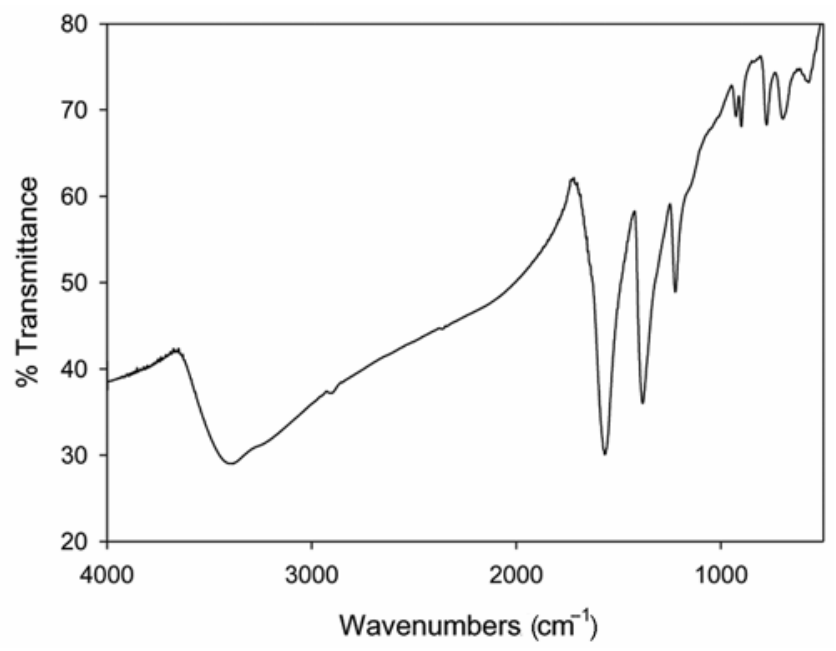

Figure 2. FTIR spectra of TGA-capped CdSe NCs.

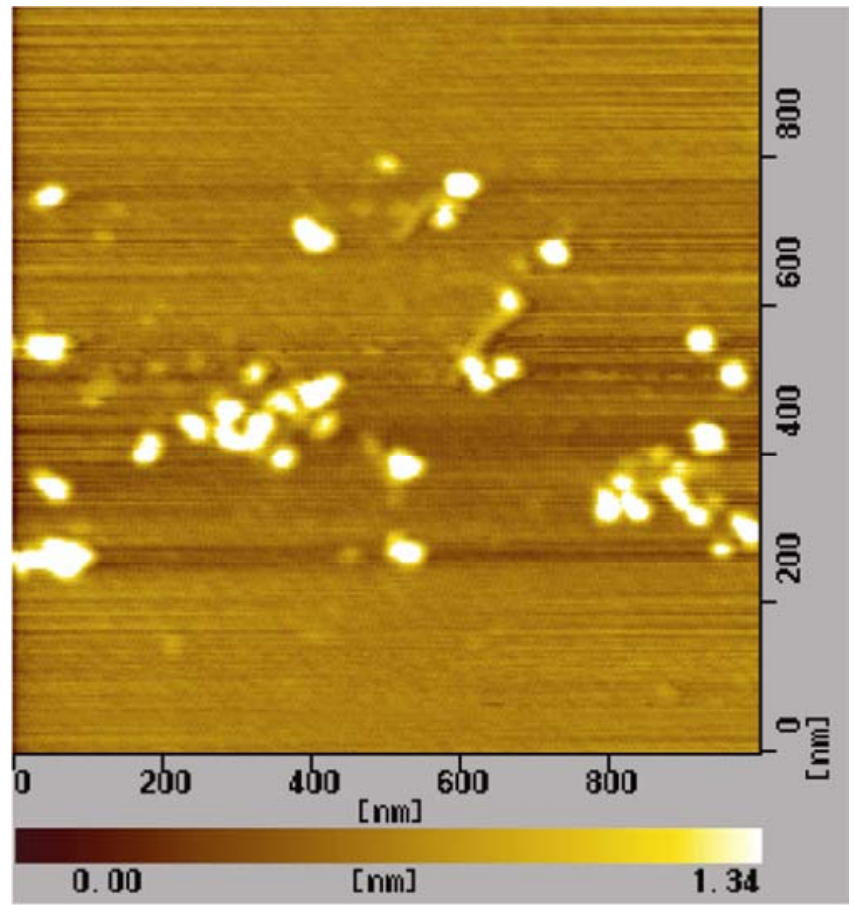

Figure 3. AFM image of CdSe NCs. plexes occurred. As $\mathrm{pH}$ enhanced, complexation happened gradually. After addition of NaHSe solution, the more the complexation happened, the more CdSe with lower defect produced. On the other hand, increasing the amount of $\mathrm{OH}^{-}$can favour the reaction between $\mathrm{Cd}^{2+}$ and $\mathrm{HSe}^{-}$. As $\mathrm{pH}$ was higher than 10.56 in precursor solution, the concentration of ${ }^{-} \mathrm{SCH}_{2} \mathrm{COO}^{-}$was higher than that of $\mathrm{HSCH}_{2} \mathrm{COO}^{-}$, it was easy to get $\mathrm{CdSe} \mathrm{NCs}$ with high quality, so the QY of sample 4 could reach as high as $1.9 \%$.

To further confirm the formation of CdSe NCs and investigate the interaction between TGA and CdSe NCs, the FTIR spectrometry was measured. As shown in figure 2 , a broad absorption band around $3400 \mathrm{~cm}^{-1}$ was assigned to $\mathrm{O}-\mathrm{H}$ vibration of the absorbed $\mathrm{H}_{2} \mathrm{O}$. An absorption band due to $\mathrm{S}-\mathrm{H}$ vibration observed at $2560 \mathrm{~cm}^{-1}$ disappeared. The characteristic absorption band of $\mathrm{C}=\mathrm{O}$ vibration was shifted from $1700 \mathrm{~cm}^{-1}$ to $1556 \mathrm{~cm}^{-1}$. Therefore, these results strongly suggest that the thiol groups of TGA coordinated with $\mathrm{Cd}^{2+}$ ions on the NCs surface, and the hydrophilic hydroxyl groups faced outward, making NCs water-soluble.

The AFM image of sample 3 in figure 3 showed that the NCs were ball-shaped with good dispersibility. The powder XRD pattern of sample 4 is presented in figure 4 . From the XRD pattern, three typical distinct features of the zinc-blended structure can be distinguished: the one at $2 \theta=25 \cdot 3^{\circ}$ is due to the (111) reflection, and the other two appearing at $2 \theta=42.0^{\circ}$ and $49.7^{\circ}$ result from the (220) and (311) reflections (Joint Committee on Powder Diffraction Standards file No. 19-0191), respectively. Moreover, no typical diffraction of the wurtzite lattice structure can be found, which further confirms the cubic zinc-blended structure.

\section{Conclusions}

In conclusion, a rapid and simple method for synthesizing TGA-capped CdSe NCs at room temperature was reported

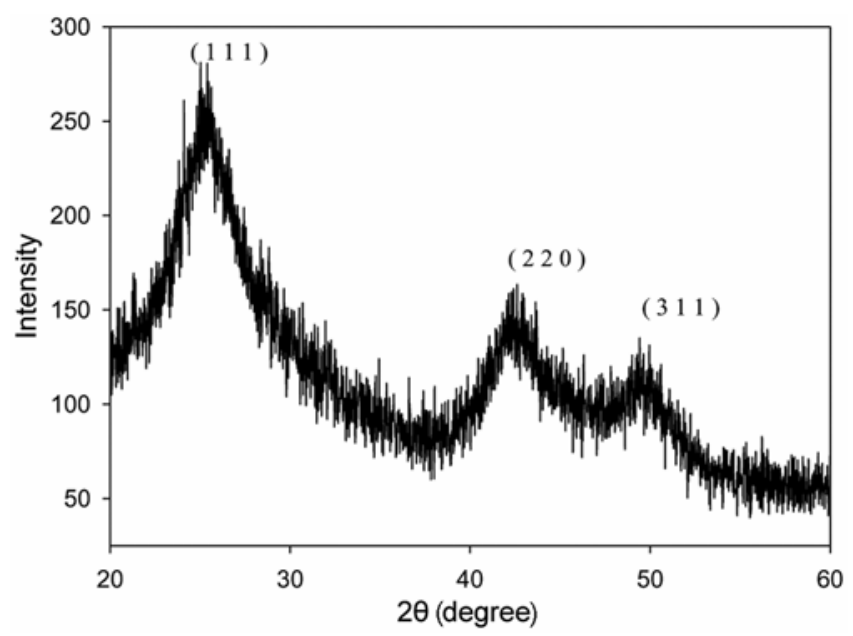

Figure 4. XRD pattern of CdSe NCs. 
in this paper. The products were ball-shaped with zinc-blended structure. The technique makes the synthesis of water-soluble CdSe NCs convenient, economic and safe.

\section{Acknowledgement}

Financial support from the scientific research fund of Guangxi University (No. X081057) is gratefully acknowledged.

\section{References}

Bowers M J, McBride J R and Rosenthal S J 2005 J. Am. Chem. Soc. 12715378

Chen S T, Zhang X L, Zhao Y B, Yan J L and Tan W H 2009 Mater. Lett. 63712

Chen X F, Hutchison J L, Dobson P J and Wakefield G $2008 \mathrm{~J}$. Colloid \& Interface Sci. 319140

Deng D W, Yu J S and Pan Y 2006 J. Colloid \& Interface Sci. 299225
Gao M Y, Kirstein S, Mohwald H, Rogach A L, Kornowski A and Eychmuller A 1998 J. Phys. Chem. B102 8360

Gaponik N, Talapin D V, Rogach A L, Hoppe K, Shevchenko E V and Kornowski A 2002 J. Phys. Chem. B106 7177

Han H Y, Sheng Z H and Liang J G 2006 Mater. Lett. 603782

Hayes D, Micic O I, Nenadovic M T, Swayambunathan V and Meisel D 1989 J. Phys. Chem. 934603

Jasieniak J, Bullen C, Embden J V and Mulvaney P $2005 \mathrm{~J}$. Phys. Chem. B109 20665

Manoj E W, Shaukatali N I, Aparna D, Aniket R T, Renu P, Sulabba K K and Santosh K H 2008 Bull. Mater. Sci. 31291

Murray C B, Norris D J and Bawendi M G 1993 J. Am. Chem. Soc. 1158706

Peng Z A and Peng X G $2001 \mathrm{~J}$. Am. Chem. Soc. 123183

Rogach A L, Kornowski A, Gao M Y, Eychmuller A and Weller H 1999 J. Phys. Chem. B103 3065

Rogach A L, Nagesha D, Ostrander J W, Giersig M and Kotov N A 2000 Chem. Mater. 122676

Xia Y S and Zhu C Q 2008 Mater. Lett. 622103

Yu W W, Qu L H, Guo W Z and Peng X G 2003 Chem. Mater. 152854

Zhu J J, Palchik O, Chen S G and Gedanken A 2000 J. Phys. Chem. B104 7344 